\title{
La comprensión lectora, una estrategia que se comunica con base en vocabulario, lenguaje y predicción ${ }^{*}$
}

\author{
Janeiro Jiménez Atencio \\ Institución Educativa Nuestras Señora de las Mercedes de Río Quito, Chocó, Colombia \\ riobrazil0617@gmail.com \\ Jorge Luis Murillo López \\ Diócesis de Quibdó, Chocó, Colombia \\ abelmurillo40@gmail.com \\ Luis Fernando Martínez Lozano \\ Diócesis de Quibdó, Chocó, Colombia \\ nandiferoparro@gmail.com
}

\section{RESUMEN}

El presente artículo es producto de un proyecto de investigación en el contexto de la Maestría en Educación de la Universidad de Medellín, cuyo objetivo fue fortalecer la comprensión lectora en los estudiantes del grado noveno de la Institución Educativa de Nuestra Señora de las Mercedes, mediante la implementación de una secuencia didáctica relacionada con la estrategia vocabulario, lenguaje y predicción (VLP). La recolección de la información se hizo mediante entrevistas, ejercicios en clase por parte de los investigadores quienes tuvieron como base los textos narrativos de la literatura afrocolombiana. Las variables se midieron con pruebas relacionadas con los niveles de lectura sintáctica, semántica y pragmática. Los resultados se expresaron de acuerdo a cada nivel específico. Estos revelan que los estudiantes tenían un bajo nivel de lectura, no reconocían correctamente la estructura de los textos, no encontraban las ideas principales, ni realizaban inferencias. Tras la implementación de la secuencia didáctica se observan mejoras importantes en sus desempeños que se sustentan en los procedimientos realizados.

Palabras clave: comprensión; cultura; narración; lectura; lector; literatura.

Cómo citar: Jiménez Atencio, J., Murillo López, J. y Martínez Lozano, L. F. (2019). La comprensión lectora, una estrategia que se comunica con base en vocabulario, lenguaje y predicción. Ciencias Sociales y Educación, 8(16), 113-132. DOI: https://doi.org/10.22395/csye.v8n16a7

Recibido: 28 de julio de 2019.

Aprobado: 12 de octubre de 2019. 


\section{Reading Comprehension, a Strategy Communicated Through Vocabulary, Language and Prediction}

\section{ABSTRACT}

This article is derived from a research project in the context of the Master in Education of Universidad de Medellín, which the main objective was strengthening the reading comprehension in 9thgrade students from the Nuestra Señora de las Mercedes school through the implementation of a didactic sequence related with the vocabulary, language, and prediction strategy. The information collection was made through interviews and class exercises made by the researchers through Afro-Colombian literature narrative texts. The variables were measured with tests focused on the syntactic, semantic and pragmatics levels- The results were expressed in accordance with each level. These reveal that the students have a low level of reading comprehension, they do not recognize correctly the structure of the texts, they did not found the main ideas nor made inferences. After implementing the didactic sequence, seve-ral improvements were identified in their performance. This can be evidenced in the performed procedures.

Keywords: comprehension; culture; narrative; reading; reader; literature.

\section{Compreensão leitora: uma estratégia que se comunica com base em vocabulário, linguagem e predição}

\section{RESUMO}

Este artigo é produto do projeto de pesquisa no âmbito do mestrado em Educação da Universidad de Medellín, Colômbia, cujo objetivo foi fortalecer a compreensão leitora nos estudantes do $9^{\circ}$ grau da Instituição Educativa de Nuestra Señora de las Mercedes, por meio da implantação de uma sequência didática relacionada com a estratégia vocabulário, linguagem e predição. A coleta da informação foi realizada por entrevistas, exercícios em aula por parte dos pesquisadores, os quais tiveram como base para desenvolver este trabalho de pesquisa os textos narrativos da literatura afro-colombiana. As variáveis foram medidas com testes relacionados com os níveis de leitura sintático, semântico e pragmático. Os resultados foram expressos de acordo com cada nível específico e revelaram que os estudantes têm um baixo nível de leitura, não reconhecem adequadamente a estrutura dos textos, não encontram as ideias principais nem realizam inferências. Após a implantação da sequência didática, são observadas melhorias importantes no desempenho deles apoiadas nos procedimentos realizados.

Palavras-chave: compreensão; cultura; narração; leitura; leitor; literatura. 


\section{Introducción}

La intención fundamental del presente texto es presentar brevemente las dificultades de la comprensión de lectura en los estudiantes del grado noveno de la Institución Educativa Nuestra Señora de las Mercedes de Río Quito. En este sentido, la importancia de este escrito es describir algunos factores presentes en el medio en el que se desenvuelven los estudiantes a la hora de leer, interpretar, analizar y entender. La población estuvo representada por veintitrés estudiantes del grado noveno, porque son los estudiantes que desde las perspectivas y experiencias de los investigadores presentaron mayor grado de insuficiencia a la hora de comprender lo que leían y escribían a partir de los cuentos Alto Congo, Los caminos de la libertad, Valle del río Cauca, Porque así era la gente, Tío conejo y tía zorra, Tío tigre y tío conejo, Hermano araña, hermano tigre y el almuerzo de mantequilla y La aventura de tío conejo.

La metodología es un conjunto de herramientas. En otras palabras, la metodología entendida como el conjunto de herramientas que permiten transitar por un camino en el contexto de la investigación, tuvo una estrategia metodológica denominada acción participativa. Esta metodología implica la presencia de un observador que consigna la información y datos de lo observado como una manera de identificar, describir, analizar e interpretar el objeto de estudio, en este caso la comprensión lectora de los veintitrés estudiantes del grado noveno de la Institución Educativa Nuestra Señora de las Mercedes de Río Quito.

La estrategia de acción participación es la adecuada en este tipo de investigación debido a que se "Está interviniendo en su contexto y a unos sujetos" (González, 2012, p. 6). En este caso los sujetos de la investigación son los veintitrés estudiantes del grado noveno, quienes se encontraron comprometidos contribuyendo a identificar y elaborar una solución al problema estudiado.

La estrategia metodológica acción participativa tiene antecedentes que se remontan a la década de los años cuarenta del siglo XX. Kurt Lewin (1939) entendió esta metodología como un proceso continuo en espiral por el que se analizaban los hechos, se conceptualizaban los problemas, se planificaban las acciones pertinentes y se ejecutaban para luego pasar a un nuevo proceso de conceptualización. La manera como Lewin concebía este proceso estaba cargado de supuestos elitistas y de concepciones de cambio social.

Las técnicas empleadas estuvieron determinadas por el uso de textos narrativos de la literatura afrocolombiana que se tienen en la institución donde se realizó la investigación. Los textos narrativos de la literatura afrocolombiana son posibilidades para mejorar la comprensión lectora de los estudiantes, toda vez que estos tienen la fuerza de transmitir una sabiduría 
porque responden a una realidad vivida en la historia misma de su gente, es decir, comparte un conocimiento impregnado de identidad. Esta realidad permite que los estudiantes comprendan e interpreten no solo un texto, sino todo su entorno vital.

Los resultados parciales que se pueden recibir como una discusión parcial, estuvieron determinados por las dificultades manifiestas que tienen los estudiantes a la hora de leer, entender, analizar e interpretar los textos. Cuando esto sucede hay mayores posibilidades de desestabilizar sus procesos de aprendizajes, los cuales se manifiestan en que no recuperan información explícita del contenido del texto, no identifican la estructura explícita del texto y no reconocen información explícita sobre los propósitos del texto. Además, se reduce la capacidad de comprender lo que se asocia a la disposición con la que el estudiante se acerca al texto, la relación simbiótica, su atracción, que finalmente desembocará en una apropiación y relectura de su realidad.

En esto radica la importancia de los textos narrativos afrocolombianos como una posibilidad que busca suplir la insuficiencia de la comprensión lectora de los estudiantes del grado noveno de la Institución Educativa Nuestra Señora de las Mercedes de Río Quito, debido a que estas lecturas están cargadas de significados que se encuentran a la base de una realidad con una referencia ancestral, cultural y de arraigo; son un tipo de lectura con significado contextualizado para el estudiante. Por lo tanto, se escogió una secuencia didáctica relacionada con la estrategia: vocabulario, lenguaje y predicción (VLP), la cual ha sido modificada según las observaciones y necesidades de los estudiantes, a partir del uso de textos narrativos de la literatura afrocolombiana. Esta facilita el reconocimiento y enriquecimiento de nuevas palabras que los llevan a la predicción de situaciones y análisis de inferencias en el proceso lector.

Con pretensiones muy amplias surge en América Latina una nueva propuesta metodológica con el fin de contribuir a que se produzcan cambios radicales a nivel social. La IAP nace en los años setenta. En el año 1977 este método queda desarrollado en una reunión que se llevó a cabo en Cartagena.

La IAP fue asumida paulatinamente por las ciencias humanas, las ciencias de la educación, la pastoral y la teología, desde esas orientaciones iniciales de la sociología. Es en este periodo donde se inicia el llamado proceso de reconceptualización del trabajo social, lo que supone superar la politicidad y la ideologicidad que lo había caracterizado da origen a diferentes tipos de reformas metodológicas, todas ellas intentaron impulsar a los sectores populares y procurar que las intervenciones tiendan a producir transformaciones sociales (Ander-Egg, 2003, p. 32). 
La IAP se compone de tres términos. Se trata de un sistema reflexivo, sintético, controlado y crítico que tiene por finalidad estudiar algunos aspectos de la realidad:

La investigación [...] constituye un conjunto de procedimientos operacionales y técnicos para adquirir un conocimiento útil para la población, con el propósito de que pueda actuar transformando la realidad social en la que se inserta. Por otro lado, facilita a la población involucrada los conocimientos necesarios para actuar con el propósito de resolver algunos de sus problemas o satisfacer algunas necesidades. (Ander-Egg, 2003, p. 32).

Ander-Egg (2003) afirma que la acción "permite que la gente involucrada conozca críticamente el porqué de sus problemas y necesidades, descubra más intereses reales y, teniendo en cuenta sus recursos emprenda acciones para transformar su realidad" (p. 33).

La Participación para Ander-Egg (2003) es una actividad en la cual están involucrados todos los agentes de la investigación, investigadores y los destinatarios de la investigación, "[a] los cuales no se les considera objetos pasivos de la investigación, sino más bien sujetos activos que contribuyen a conocer y transformar la realidad en la que se encuentran inmersos" (p. 32).

En este sentido, para Ander-Egg (2003) acción y participación tienen como objetivo de estudio establecer lo que se va a estudiar, el cual se decide por lo que interesa a un grupo de personas, a un colectivo. Establece la finalidad última de estudio, es decir, para qué es la transformación del problema que afecta a los involucrados, la intención de todo el estudio investigativo se orienta a intervenir la vida social. Fija un proceso secuencial: "conocer-actuar-transformar, lo que permite una intervención al sensibilizar a la población sobre sus propios problemas, profundizar en el análisis de su propia situación u organizar y movilizar a los participantes" (Ander-Egg, 2003, p. 32). De alguna manera, procura establecer una dialéctica entre el conocimiento y la acción, actúa sobre la realidad, se articula la investigación y la práctica. También exige formas de comunicación entre iguales con el propósito de realizar un trabajo común e invita a investigadores y agentes a investigar, a tener un compromiso serio en el programa, llamándolos a participar y transformar el contexto social. Es una propuesta metodológica que encierra limitaciones y posibilidades.

Para el análisis de los resultados de acuerdo con el método asumido, se siguen las siguientes etapas: el diario de campo, portafolio y pos-test. En la etapa del diario de campo se accedió a los puntos de vista o relatos que aportan los participantes acerca de la caracterización de comprensión lectora por parte del investigador. Lo descrito se asume como una unidad de sentido. Sin embargo, en este primer momento el acercamiento implica privilegiadamente conservar los 
aportes de los participantes sin alterarlos, reflejando lo más fielmente posible la realidad vivida por ellos en relación al tema de investigación.

En un segundo momento, la etapa del portafolio, instrumento de registro que llevaban los estudiantes del grado noveno, se consignaron y verificaron el proceso de la comprensión lectora de acuerdo con el ritmo de las actividades realizadas por ellos mismos. Por tal motivo, se rastrean en la información las unidades de sentido concebidas por algunos, tales como categorías de análisis. A través de estas, las descripciones pasan de opiniones o vivencias empíricas a materiales de análisis que son objeto de reflexión que entran en interacción con el proceso de la comprensión lectora. La vivencia se vuelve fenómeno en la medida en que hace visible algo esencial. El momento e instrumento del portafolio implican el estudio y análisis en el contexto donde se realizó la presente investigación.

El último momento del pos-test, permitió la consolidación de la reflexión final representada en la consolidación de la descripción general, la lectura reflexiva de cada descripción, la identificación de los temas centrales o categorías iniciales y emergentes, el registro de dichas categorías esenciales, la identificación de nuevas categorías, la descripción de lo extraído como una estructura o relato global, la relación de lo obtenido con las investigaciones previas y la consolidación final del análisis.

\section{Los actos del habla y su relación con la lectura}

Los actos del habla y la relación con el proceso de la lectura a partir de la secuencia didáctica vocabulario, lenguaje y predicción (VLP) posibilitan que los cuentos Alto Congo, Los caminos de la libertad, Valle del río Cauca, Porque así era la gente, Tío conejo y tía zorra, Tío tigre y tío conejo, Hermano araña, hermano tigre y el almuerzo de mantequilla y La aventura de tío conejo, promuevan el mejoramiento de la comprensión lectora en los estudiantes del grado noveno de la Institución Educativa Nuestra Señora de las Mercedes de Río Quito.

Los seres humanos siempre están en comunicación constante. Para ello, se valen de signos, expresiones, vocablos y usos culturales presentes en los entornos vitales. De ahí que esa comunicación sea exacta y precisa respecto al sujeto emisor como al receptor y que las palabras estén llenas de contenidos que van más allá de su composición gramatical. Por citar un ejemplo, la expresión "iHoy hay barrio!" en el contexto de la comunidad de Villa Conto, hace referencia a que hay encuentro de fútbol interbarrial. Si el oyente no está relacionado con este contexto particular, será muy difícil que interprete el mensaje que hay detrás de dicha expresión. Hablar pasa a ser un acto social que facilita a los miembros 
de un grupo, cualquiera que sea, generar canales de comunicación y así entrar en una interacción mutua. Por lo tanto:

El término clave desarrollado principalmente por filósofos como Austin y Searle en la década del 60, es el de acto de habla (speech act). Un acto de habla es el acto llevado a cabo cuando un hablante produce un enunciado en una lengua natural en un tipo específico de situación comunicativa. Tal situación recibe el nombre de contexto. Ello significa que un acto de habla no es solo un acto de «hablar» o de "querer decir», sino, además, y de manera decisiva, un acto social, por medio del cual los miembros de una comunidad hablante entran en interacción mutua (Mayoral, 1987, p. 172).

Los actos del habla en el desarrollo de la comprensión lectora hacen posible que las palabras tengan significado dentro en un grupo social específico. Otro autor que relaciona el término antes descrito es Bachioqui (2010) quien afirma: "detrás de toda emisión existe una intención, en otras palabras, cuando un orador pronuncia una oración esta no solo describe o informar algo, sino que representa una acción por sí sola" (p. 336). Solo cuando se es capaz de interpretar y contextualizar las palabras correctamente, se posee la auténtica comunicación entre las partes involucradas.

Una comunicación auténtica involucra a dos o más individuos entre los cuales se desarrollan una serie de palabras, signos, imágenes o escritos cargados de diversos significados que serán reinterpretadas en cada oyente de manera subjetiva, generando así el diálogo y la comprensión en lo que a ambos interesa o desean. La comunicación, aunque es un lenguaje universalmente reconocido en cada ser vivo, adquiere un factor de complejidad mayor en individuos como el Homo sapiens, porque en este entran a jugar un papel importante los actos del habla por su capacidad de pensar y elaborar nuevas ideas, lo que implica que cada palabra adquiere una nueva significación subjetiva que depende del oyente receptor.

La teoría de "Los actos del habla", fue enunciada por el filósofo John L. Austin perteneciente a la filosofía analítica o filosofía del lenguaje desarrollada a mediados del siglo XX, que centra su atención en el análisis del lenguaje. La importancia de esta teoría radica en que permite identificar los aspectos más significativos que están dentro del discurso enunciado y son significativos para el oyente, lo hacen válido, relevante y significativo para el receptor. En su libro How to Do Things with Words (1962) propone:

En 1962, con su libro "How to Do Things with Words" (Cómo hacer las cosas con las palabras), John Austin se convirtió en el padre de la teoría de los actos del habla, al establecer que al decir una cosa también se hacía otra, además del simple hecho de decirla, como pedir o prometer. Más tarde, John Searle retomó y perfeccionó la teoría de Austin sobre los actos del habla e hizo una extensión del análisis; en esta, Searle propone los actos de habla, actos lingüísticos o actos del lenguaje para estudiar 
algunos problemas de la filosofía del lenguaje; al mismo tiempo establece que es importante estudiarlos ya que hablar una lengua consiste en realizar actos de habla como hacer enunciados, dar órdenes, plantear preguntas (Bachioqui, 2010, p. 336).

Esto quiere decir que toda palabra tiene una fuerza cargada de múltiples significados que están correlacionados con su estructura gramatical, corporal y contextualizada del sujeto origen y la interpretación propia del sujeto receptor. Los actos del habla permiten un canal de comunicación e interacción entre el emisor y el receptor en la medida en que este último logre, en palabras de Barchioqui (2010) "llevar la interpretación más allá de las palabras" (p. 346).

De allí la necesidad de saber leer entre líneas los contenidos profundos de las palabras. Así llegamos al punto de entender que todos los actos del habla están estrechamente relacionados con la lectura, este elemento fundante y fundamental que subyace en todos los aspectos cotidianos de comunicación en una sociedad. Si la sociedad está inmersa en la comunicación como mecanismo de interacción, se hace necesario que esa lectura contextualizada le permita al individuo, sujeto de un grupo social, leer e interpretar esos actos de habla para integrarse y generar nuevos aprendizajes:

La lectura es uno de los aprendizajes más importantes que realizamos en la vida. De ella dependen en gran medida otros aprendizajes. La lectura se relaciona con el aprendizaje, el desarrollo del pensamiento y las capacidades cognitivas superiores como las reflexivas y críticas. Aprender a leer es aprender a pensar, generar ideas, relacionarlas o compararlas con otras ideas con experiencias anteriores, a analizarlas, a deducir, inferir y comprender. La lectura es una herramienta para lograr integrarse a la vida laboral, social y afectiva (Maqueo, 2006, p. 207).

En este sentido, la lectura es un proceso denso. Sin embargo, el acto de leer es una relación tripartita: yo, tú, ellos. Como herramienta del enriquecimiento de la espiritualidad (relaciones armoniosas), hace que todos los individuos se vinculen y participen de la riqueza que generan dichos actos de habla. De esta manera, se pueden realizar como personas capaces de entender y aportar aprendizajes surgidos a partir de la lectura contextualizada de los actos del habla. Una lectura contextualizada hace referencia a la interpretación propia que cada individuo hace desde el punto de vista cultural, social, histórico, etc., de lo que lee o escucha como oyente receptor.

Cuando se comprende el sentido profundo del texto, se puede decir que realmente se está haciendo una verdadera lectura más allá de las simples expresiones o composición gramatical. Maqueo (2006) propone al respecto: "el significado del texto lo construye el lector cuando elabora una interpretación global de él a todo lo largo de la lectura" (p. 210). Dicha interpretación siempre 
estará permeada o modificada por realidades propias del individuo, como la cultura, su historia, coyunturas sociopolíticas, etc., que dan un nuevo sentido a la vida del oyente. Todo texto modifica un contexto individual y colectivo en tiempos o circunstancias ajenas a lo que su autor pretendió decir en su momento, debido a que su interpretación final depende exclusivamente del oyente receptor subjetivo.

La comunicación hace parte de las necesidades más esenciales de todos los seres vivos. Responde a muchos usos y está determinada tanto por los contextos como por su complejidad gramatical, además de la interpretación del oyente; de este depende en gran medida la transformación material de lo expresado por el hablante. La comunicación requiere de unos aspectos o dimensiones del lenguaje en tanto signo, que aunque tienen puntos de vista distintos se complementan para contribuir a la comprensión del fenómeno del signo:

La sintaxis es el estudio de qué y cómo se dice o expresa (algo); la semántica el estudio de qué se quiere decir (al decir algo), y la pragmática el estudio de qué se hace (al decir algo). En otras palabras, la pragmática es aquella parte del estudio del lenguaje que centra su atención en la acción. Una sintaxis especifica las reglas según las cuales una expresión está "bien formada", y una semántica especifica las reglas de acuerdo con las cuales dicha expresión es "portadora de significado", la pragmática se ocupa de la formulación de las reglas según las cuales un acto verbal es apropiado (appropriate) en relación con un contexto. (Mayoral,1987, p. 172)

Los actos del habla contienen en sí mismos una estructura lógica que promueve el diálogo. Esto permite que dicho acto de habla genere una comunicación enmarcada en una estructura gramatical para poder ser entendido, captado e interpretado por el oyente. Estas estructuras semióticas del lenguaje son necesarias en la construcción lingüística de las oraciones o enunciados. Sin embargo, no se puede dejar de lado el factor importante acerca de que la comunicación es ante todo acciones sociales. La comunicación no se puede desvincular de las manifestaciones espontáneas de los individuos, y está enclavada en realidades contextualizadas que facilitan el entendimiento y la comprensión de los actos del habla en los miembros de un grupo social o comunidad.

En toda comunicación literaria se desarrollan aspectos semióticos, a saber: sintáctica (qué y cómo se expresa algo), semánticos (los significados de las palabras, expresiones y oraciones) y pragmáticos (que se hace al decir algo), que hacen parte del constitutivo de un acto de habla. Todos estos aspectos, aunque juegan un papel preponderante en la estructura de la misma, no determinan su significado respecto a lo que puede concluir o significar cuando es percibida por el oyente. Moya (2009) comenta al respecto: "para la pragmática, los elementos extralingüísticos desempeñan un papel importante en la interpretación de cualquier evento comunicativo real, pues existe una distancia entre lo que decimos literalmente y lo que realmente queremos decir" (p. 229). 
Las palabras o actos de habla no siempre transmiten un solo y único contenido, estos varían de acuerdo a la contextualización que el oyente finalmente le atribuye. El autor relaciona esto como un juego lingüístico: "el lenguaje consiste en mil juegos. Lo que se dice depende de su contexto, es decir, el significado de una palabra depende de su uso en una situación particular" (Moza, 2009, p. 233). Las palabras son lo que el oyente quiere que sean y signifiquen. Están determinadas por la significación profunda que el oyente dentro de su contexto quiere que sean.

Toda lectura tiene una interpretación contextualizada, la cual hace parte de la comunicación de cada individuo que dista mucho de la idea primigenia de su autor o de lo que él quiso decir. En este sentido, Moya (2009) citando a Austin plantea: "lo que hacemos con las palabras es lo que determina su sentido. Las palabras no tienen un significado determinado, sino que este depende del contexto en el que las usamos. Hacemos cosas con palabras" (p. 232). La comunicación está determinada por las diversas interpretaciones o inferencias que hacemos de los actos del habla producidos por el hablante, no tienen límite, espacio o tiempo. Por el contrario, están supeditadas a la experiencia del oyente.

Ahora bien, cuando se plantean los niveles de lectura enfocados desde la teoría de la comunicación literaria, Araujo y Delgado (2003) definen esto como:

La teoría literaria tiene como centro de su campo a la literatura, pero este puede ser visto desde su materialidad, como arte verbal, práctica significante, acto de comunicación. Incluye las problematizaciones de lo literario y sus fronteras, la naturaleza del hecho literario, del lenguaje como representación, de la literatura como discurso ideológico [...] Las relaciones entre significado y significante, sentido, significación e interpretación. (p. 19)

En este sentido se hace referencia a la transversalidad que existe entre los elementos propios de los niveles de lectura, que dan como resultado la comunicación entre el hablante y el oyente, lo que equivale a decir que la comunicación se sirve de unos códigos semióticos necesarios para generar la comprensión. El modelo que utiliza la teoría de la comunicación es el modelo semiótico y su concepto central es el de código:

El acto de comunicar implica la remisión de una información codificada o cifrada que en manos del receptor y gracias a una clave para descifrarlo, es asequible a la comprensión. No debemos olvidar que no todo proceso comunicativo se realiza desde este modelo de código, en ciertos eventos comunicativos cotidianos predomina más la comunicación inferencial que la comunicación codificada. (Moya, 2009, p. 241)

Finalmente, es el oyente cotidiano quien termina modificando estos códigos transversales propios de la comunicación, dándole paso a la imaginación, la creatividad y el contexto para generar e interpretar sus propios actos del habla necesarios en esa comunicación: 
[.... El objetivo principal de una teoría de la comunicación es el de explicar cómo nos entendemos mediante la realización de ciertas clases de acciones que posibilitan la comunicación y de qué modo funciona todo el proceso de producción y comprensión del significado ligado a esas acciones. (Moya, 2009, p. 243)

Las acciones, gestos, contextos y usos particulares son determinantes en la interpretación final de ese acto de habla generador de comunicación. Comunicación necesaria y vital para la sociedad en la cual las personas desarrollan sus vidas, ya sea de manera individual o colectiva. La manera como se entienden e interpretan esas acciones contenedoras de significados posibilita la auténtica comunicación, el desarrollo y crecimiento de la sociedad. De esta manera, se garantiza la auténtica transmisión de sus usos, valores y costumbres para las generaciones futuras y la identidad de la cultura mediante la lectura de textos propios del contexto, como el caso del desarrollo de la comprensión lectora en los estudiantes del grado noveno de la institución que facilitó el estudio.

\section{La comprensión lectora en contexto}

A los estudiantes del grado noveno se les proporcionó a manera de diagnóstico, las lecturas de textos narrativos de la literatura afrocolombiana como posibilidad de establecer si los textos narrativos denominados, como los cuentos Alto Congo, Los caminos de la libertad, Valle del río Cauca, Porque así era la gente, Tío conejo y tía zorra, Tío tigre y tío conejo, Hermano araña, hermano tigre y el almuerzo de mantequilla y La aventura de tío conejo permitían cierto grado de comprensión en los educandos. La lectura de los cuentos anteriormente citados en el aula de clase generó en los estudiantes el reconocimiento de la importancia de los conocimientos sobre la cultura como factor importante en el proceso de la comprensión:

Dado que esto es lo que permite comprender un texto, en caso de que no existan esos conocimientos es probable que no se comprenda nada. Pensemos en un posible titular de un periódico mexicano: "El Popo amenaza de nuevo". Imaginemos que un hablante colombiano lee sin tener ninguna referencia previa, ningún conocimiento o información que le permita descifrar esa expresión. Este lector obviamente cuenta con los conocimientos formales y textuales de la lengua, dado que es hispanohablante, pero le faltan conocimientos dentro de su teoría del mundo sobre qué o quién es el Popo, en qué sentido amenaza, a quien, etcétera. (Maqueo, 2006, p. 220).

En este sentido, la lectura de textos autóctonos dentro del mundo de la comunicación posibilita el fortalecimiento del vínculo entre emisor y receptor. Asimismo, genera conocimientos previos e interés por la lectura a tratar, en este contexto los cuentos de la literatura afrocolombiana, como la búsqueda de las respuestas a las preguntas: ¿Qué dice el texto? ¿Cuáles son los personajes? 
¿Quién narra? ¿Cómo narra? ¿Cuál la moraleja del texto? En este aspecto, podemos decir que la lectura exige:

Una actividad previa a la lectura, consistente en una discusión sobre los problemas a que se enfrentan los pájaros para sobrevivir durante el invierno. Una vez que los alumnos han expresado e intercambiado sus ideas y conocimientos relacionados con el tema, el profesor los anima para que lean un artículo relacionado con el mismo asunto: indagar si las aves tienen otros problemas para sobrevivir durante las ventiscas. (Maqueo, 2006, p. 225)

Un ejercicio previo a la lectura en los estudiantes posibilita que cada uno de ellos se enfoque en el tema, la lectura y un camino posible para comprender e interpretar textos por parte de los educandos, lo que favorece una adecuada comprensión del mismo. El autor insiste en la necesidad de mejorar y apropiarse de este tipo de estrategias, aplicándolas en todas las áreas del saber, dado que la lectura es transversal en todas las asignaturas.

El hábito de la lectura tiene un componente personal, alguna motivación relacionada con el autor o el tema a leer, incluso con la historia que se cuenta y de la cual habla el texto. Siempre habrá algo detrás de cada libro abordado. Se lee porque se quiere comprender algo sucedido. Por ejemplo, el profesional busca artículos que lo renueven en relación con la carrera o campo de interés. Por tanto, no siempre es fácil iniciar a alguien en la lectura, se necesitan muchos y diversos métodos que lo atraigan, ya sea por el tema que hay entre líneas o por el autor quien la cuenta.

En este sentido, como expone Maqueo (2006): "el fracaso en la enseñanza de la comprensión lectora, en buena medida, reside en el tipo de materiales que se le presentan al alumno: distantes, sin interés para él, difíciles de comprender léxica, gramatical y temáticamente" (p. 247). Esto quiere decir que una de las tantas exigencias dentro del desarrollo de la comprensión lectora está en la selección de textos narrativos que interpelen a los estudiantes en sus respectivos contextos de aprendizajes.

\section{Componentes de la compresión lectora}

El trabajo del lector es decodificar el mensaje presentado implícita o explícitamente en el texto sin hacer referencia a sus propias experiencias, el entorno cultural en que se redactó el texto o las intenciones del autor. Lo que equivale a decir que, la comprensión de la lectura es un proceso que requiere ciertas etapas y que cada etapa exige un procedimiento como requisito que conduzca a los estudiantes a una satisfacción por lo menos parcial acerca de lo que han comprendido. Además, la comprensión de la lectura como proceso exige el de- 
sarrollo de modelos, es decir, patrones que permitan guiar a los estudiantes en el proceso de la comprensión, en este caso, de la lectura, por ejemplo:

El modelo transaccional se basa en la suposición de que un texto adquiere diversos significados para diferentes lectores, no obstante, las intenciones del autor o el contenido textual. Bajo este modelo, los lectores interpretan un texto desde la perspectiva de sus propias metas y objetivos dentro de un contexto particular. Por ello, construyen el significado con referencia al conocimiento previo del tema, experiencias lectoras anteriores y los objetivos de la situación actual. (Jackson, 1998. p. 1201).

Los resultados sitúan a la mayoría de los informantes en el modelo transaccional, el cual favorece la comprensión del texto. No obstante, en el estudio se da pie al surgimiento de modelos mixtos. Se encuentra que el acercamiento al texto, la frecuencia de lectura, la variación en estrategias, la personalización y la crítica del texto son características que se relacionan con los modelos epistemológicos de lectura. Cerchiaro, Paba y Sánchez desarrollaron en 2011 una revisión conceptual de la relación entre metacognición y comprensión lectora. Comienzan exponiendo que:

Al principio la lectura es un objeto de conocimiento, que luego se convierte — según Vygotsky - en un instrumento para asimilar conocimientos; esto se hace evidente en la vida universitaria, donde al estudiante se le exige que lea de manera intencional, autónoma, reflexiva y crítica para responder a los requerimientos académicos. Plantean que muchas de las dificultades con esta habilidad se asocian a deficiencias en procesos cognitivos y metacognitivos, teniendo en cuenta que el lenguaje es un proceso cognitivo y la lectura es una forma de lenguaje. (Cerchiaro et al., 2011, p. 100)

A manera de ejemplo, de acuerdo con el estudio que realizaron los investigadores y que anteriormente se citó, consideran que:

El componente metacognitivo juega un papel fundamental en la comprensión lectora. Se han llegado a distinguir dos componentes metacognitivos claves para regular la comprensión lectora: el conocimiento del propósito de la lectura (para qué se lee) y la autorregulación de la actividad mental para lograr ese objetivo (cómo se debe leer), la cual requiere controlar la actividad mental de una forma determinada y dirigirla hacia una meta concreta. (Cerchiaro, et al., 2011, p. 103)

Vistas así las cosas, los docentes tienen el imperativo de aplicar un modelo de clase donde los niños, niñas y jóvenes, descubran verdades que para nosotros son muy conocidas pero que para ellos serán nuevas e interesantes. Un modelo de clase que les permita ser creativos y participativos donde el educando sea capaz de desarrollar sus capacidades intelectuales y cognitivas y deje a un lado el método tradicional. Esto se logra a través de la aplicación de estrategias innovadoras.

Por consiguiente, la educación como la estrategia fundamental para que las personas alcancen su humanización, se encuentra ligada a los intereses y 
necesidades concretas de una población capaz de ofrecer las condiciones para la igualdad y la justicia social.

Y como dice Goodman (1982), aprender a leer implica el desarrollo de estrategias para obtener sentido del texto. Implica el desarrollo de esquemas acerca de la información que es representada en los textos. Esto solamente puede ocurrir si los lectores principiantes están respondiendo a textos significativos que son interesantes y tienen sentido para ellos.

En este sentido, el desarrollo del lenguaje oral y escrito no son realmente muy diferentes. Ambos dependen del desarrollo del proceso a través de su utilización funcional. Por la misma razón, se cree que solamente se aprende a leer y a escribir una vez. Si se es letrado en una lengua es muy fácil llegar a ser letrado en otra. Más aún, una vía importante para aprender una segunda lengua es a través de la lectura. A menudo la primera lengua procesa una segunda lengua que va a ser adquirida por personas que ya son letradas en otra lengua.

No es más difícil aprender a leer y a escribir que aprender el lenguaje oral. Pero los programas de instrucción deben apartarse de las tradiciones de tratar la lengua escrita como un tema escolar para ser dominado. Más bien deben basarse en una comprensión del proceso y en el crecimiento natural del niño dentro de la lengua escrita.

\section{Niveles de la comprensión lectora}

Parafraseando a Solé (2006), en el desarrollo del ejercicio de leer se puede entender que leer es un proceso de interacción entre el lector y el texto, lo que viene a significar que leer es una necesidad desde una información captada por el lector que tiene que ejercitarse para poder descifrar los símbolos y códigos que se encuentran en la lectura. Esto constituye un imperativo que viene a significante, una tarea para cada lector en miras de comprender lo leído y que como resultado se produzca una comprensión parcial o total del texto. En esta línea lo plantea también Defior (2000): "leer es un esfuerzo en busca de significados, es una construcción activa del sujeto mediante el uso de todo tipo de claves y estrategias" (p. 39).

Esto quiere decir que el proceso de la comprensión lectora demanda sentidos, entendiendo estos como los fundamentos que orientan un hacia un horizonte y una finalidad. El horizonte tiene una base y esa base está determinada por cada uno de los respectivos niveles como lo son: sintáctico, semántico, pragmático e inferencial; la finalidad se muestra mediante el grado de la comprensión de lo leído por cada estudiante del grado noveno de la Institución Educativa Nuestra Señora de las Mercedes de Río Quito. 
La presencia de los cuatro niveles de lectura anunciados anteriormente, hace que el desarrollo de los dos primeros niveles ayuden a los estudiantes a comprender y reconocer las palabras dentro de la estructura gramatical y el significado de estas. Sin embargo, estos dos niveles se quedan desarticulados porque para los docentes el hecho de que el estudiante conozca las palabras y sus significados no quiere decir que haya alcanzado el nivel de comprensión lectora.

Según Cassany, Luna y Sanz (1998), "la lectura es uno de los aprendizajes más importantes que proporciona la escuela, esto se logra a través de la lectura de libros, periódicos, revistas y otros, la cual nos proporciona conocimientos en cualquier disciplina del saber humano" (p. 11). También la lectura se puede ver y aplicar como un proceso que implica la articulación entre lo visto, lo leído y su significado que transforma la vida del lector. Por lo tanto, "la lectura es el instrumento que enriquece y estimula intelectualmente al lector" (Condemarín, 2001, p. 58). Con base en esto, se puede constatar que "el lenguaje escrito constituye la meta última de la lectura, pues incluye entender la esencia del significado a través de su relación con otras ideas, hacer inferencias, establecer comparaciones y formularse preguntas relacionadas con él" (Condemarín, 2001, p. 59).

La lectura no solo se puede aceptar como proceso, sino que también puede ser asumida como sistema y como sistema tiene una estructura. Dentro de la estructura existen etapas y cada una tiene un nivel de comprensión de lo leído. La lectura es un mensaje. Un mensaje que exige ser descifrado. Un mensaje que después de ser leído amerita ser entendido, analizado e interpretado.

Sánchez (2011), considera que el mensaje tiene una instancia:

Para que un mensaje sea procesado tiene que ser previamente recogido y analizado por los sentidos, que son los mecanismos perceptivos que extraen la información gráfica de la hoja y lo almacenan durante un tiempo muy breve en un almacén sensorial llamado memoria icónica. (p. 42)

En este sentido, el nivel sintáctico propone dentro de la comprensión lectora el requerimiento de que exista la fusión de lo que se ve - percepción, símbolos, palabras, vocabulario-, con el significado de los objetos contemplados y los del mensaje que se anuncia mediante los elementos de las oraciones gramaticales. En este proceso el estudiante pasa a ocupar el último lugar, un lugar relevante porque debe "extraer el mensaje de la oración para integrarlo con sus conocimientos. Solo cuando ha integrado la información en la memoria se puede decir que ha terminado el proceso de comprensión" (Sánchez, 2011, p. 39).

Condemarín (2001), define a la comprensión lectora como un proceso interactivo, recibido de la información del lector de acuerdo a la edad, grado de instrucción, nivel socioeconómico, contenido y complejidad del texto, factores 
psicolingüísticos sintácticos y semánticos para el logro del significado. Lo que viene a significar para el proceso de la enseñanza y el aprendizaje que:

La comprensión a que el lector llega se deriva de sus experiencias previas acumuladas, experiencias que se presentan en el juego y se unen a medida que codifica las palabras, frases, párrafos e ideas del autor. La lectura es un medio, que nos acerca a la comprensión de los demás, de los hechos que han vivido y descubierto, de lo que han concebido en su mente o que han imaginado. (Sánchez, 2011, p. 42)

\section{Nivel sintáctico}

Según Cueto (1999), el procesamiento sintáctico es el conocimiento acerca de la estructura del lenguaje a través del cual el lector infiere la estructura profunda para llegar al significado. Aunque el reconocimiento de palabras o procesamiento léxico es un componente necesario para llegar a entender el mensaje presente en el texto escrito, no es suficiente. Las palabras aisladas no transmiten ninguna información nueva, sino que es en la relación entre ellas donde se encuentra el mensaje. Este nivel exige un análisis que está determinado por "tres operaciones principales", según Sánchez (2011):

- Asignación de las etiquetas correspondientes a las distintas áreas de palabras que componen la oración, sintagma nominal, verbo, frase subordinada, etc.

- Especificación de las relaciones existentes entre estos componentes.

- Construcción de la estructura correspondiente, mediante ordenamiento jerárquico de los componentes.

Para la comprensión lectora es necesario que este nivel aparezca, debido a que la comprensión lectora como proceso permite el desarrollo adecuado del análisis de la oración gramatical:

El agrupamiento correcto de las palabras de una oración en sus constituyentes, así como el establecimiento de las interrelaciones entre los constituyentes, los consigue el analizado sintáctico gracias a una serie de claves presentes en la oración. Estas son algunas de las más importantes: el orden de las palabras, palabras funcionales, significado de palabras. (Sánchez, 2011, p. 45)

\section{Nivel semántico}

Según Sánchez (2011), "el procesamiento semántico incluye tanto la experiencia como el conocimiento general y conceptual del lector, permite dar el sentido de lo que lee, el siguiente y último de los procesos que interviene en la comprensión lectora" (p. 47). El proceso de la comprensión lectora es determinante para extraer el significado de la oración o texto y de integrarlo junto con el resto de los conocimientos que posee el lector. Esta operación consta por consiguiente de dos subprocesos: 
La extracción del significado y la integración en la memoria. La extracción del significado consiste en construir una representación o estructura semántica de la oración o texto en la que vienen indicados los papeles de actuación de los elementos que intervienen en la acción señalada por el verbo. Integrar el significado en los conocimientos del lector representa que el proceso de comprensión no termina en la extracción del significado de la oración o texto, sino cuando se integra ese significado en la memoria, ya que comprender no solo implica construir una estructura sino además añadir esa nueva estructura con los conocimientos que el lector ya posee. (Sánchez, 2011, p. 48)

El mensaje leído desde este nivel permite integrar los mensajes en la memoria como una necesidad que tiene como finalidad: "establecer un vínculo entre esta nueva estructura y los conocimientos que ya se poseen, y este vínculo se consigue introduciendo en el mensaje información que el lector ya posee y que le servirá para activar los conocimientos correspondientes" (Sánchez, 2011, p. 49).

Por la presencia del nivel semántico es que el estudiante del grado noveno puede extraer significado para luego integrarlo a los conocimientos adquiridos y, aún más, puede fusionarlo a la vida cotidiana que se desarrolla en un determinado contexto. Como lo expone Cueto (1999) "lo principal del procesamiento semántico consiste en que permite extraer el significado de la oración o texto y asimilarlo a la estructura de conocimientos que posee el lector" (p. 29).

\section{Nivel pragmático}

La lectura como ejercicio pedagógico y estrategia pedagógica que promueve la comprensión está dentro del mundo de los símbolos. Las palabras son símbolos. Lo que se lee son símbolos. Estos símbolos exigen ser articulados a un contexto para que además de ser visibles, adquieran la connotación del sentido y del significado dentro del contexto y los conocimientos de los estudiantes articulados a la medida del aprendizaje y el grado de comprensión.

Este nivel de lectura proporciona la posibilidad de interpretar. Se asume interpretar como descifrar los códigos y el mensaje de los símbolos que el autor mediante un texto, plasma ideas o teorías y fomenta con el texto que el lector desarrolle las competencias de conectar lo leído con el contexto. Este ejercicio de conexión permite que el lector no perciba el mensaje de manera superficial, sino de una forma más profunda, hasta llegar a comprender mediante la correspondencia entre el mensaje, lo que dice el texto y los múltiples significados que se pueden articular con el contexto donde se realiza la lectura, no sin antes tener en cuenta, que en este nivel de lectura, el lector alcanza las competencias de hacer conjeturas para llegar a conclusiones con respecto a lo leído. 


\section{Conclusiones}

La metodología basada en las experiencias significativas es posiblemente la mejor alternativa que se ha venido utilizando como mecanismo de ayuda y planteamiento a la salida de las problemáticas que se han presentado en los últimos años en el contexto de la educación en Colombia, específicamente en lo que respecta a la comprensión lectora en los estudiantes. Las experiencias significativas son una herramienta de expresión individual y colectiva que están permitiendo que los docentes puedan desarrollar proyectos de aula a través de una educación inclusiva. Se parte de las necesidades de los estudiantes y se tienen en cuenta los recursos de los entornos, y promoviendo en ellos el sentido de investigación y expansión del trabajo en y fuera del aula por todos los rincones del desarrollo que viven ellos.

No hay que olvidar que la realidad actual permite a la educación guiar a los estudiantes a pensar, crear, revisar, reconstruir y plantear estrategias de solución a las problemáticas que día a día se les presentan a nivel del aula, familiar, local y nacional, lo que los lleva a enfrentar las situaciones que les presenta el mundo actual. Se debe tener en cuenta la realidad social de los educandos para generar en ellos un espíritu autocrítico que los lleve a ser transformadores de su realidad y entorno; partiendo de los saberes previos y culturales que ellos tienen para entender su mundo, su realidad.

Los maestros tienen que ser sujetos políticos. Hay que saber leer el mundo, ser sujetos autocríticos para no repetir lo que han hecho los demás y no quedarse estancados ante una sociedad que día a día se hace más exigente. En la escuela o colegio, hay que darles la oportunidad a los estudiantes, para que sean artífices de su propio conocimiento a través de todo el proceso educativo, teniendo en cuenta que el conocimiento se construye entre las personas en la medida en que interactúan unas con otras, permitiéndoles ser autocríticas.

Desde una visión holística del proceso educativo, hay que reivindicar una educación centrada en los estudiantes y sus circunstancias vitales, inclusivas, lideradas por docentes que tengan y desarrollen sensibilidad en el contexto y en la historia de los estudiantes. Se necesitan unos centros que sean focos de transformación con una responsabilidad intrínsecamente asociadas al rol educativo dentro de la sociedad, compartida con otros agentes: unos centros que tomen partidos por la comunidad a la que pertenecen, den respuestas a sus inquietudes y necesidades, alienten los procesos de cambios, den voz a quienes han sido silenciados. En definitiva, que sean guías de la comunidad.

Hay que tener en cuenta que la escuela no ha de liderar necesariamente estos procesos, pero debe ser una pieza clave en los mismos en la que juegue su papel de referente en el engranaje comunitario y dentro del proceso de enseñanza- 
aprendizaje, a través de la práctica pedagógica o desarrollo de la labor docente. La educación es el pilar o guía fundamental para recomponer una sociedad que necesita estrategias para reformular un mejor ambiente social; en donde los seres humanos comprendan que a partir de las diferencias individuales se debe ser mediadores, cooperadores, concertadores en la construcción de un mundo colectivo mejor.

Teniendo en cuenta los contextos educativos del país, el primer aporte va encaminado hacia el Ministerio de Educación Nacional como ente encargado de la elección y ordenamiento de las políticas y planes educativos a desarrollar, lo que sugiere una orientación en la escogencia de estos de acuerdo a las necesidades y entornos educativos. En estos se desarrolla la actividad educativa, puesto que estos influyen directamente en los currículos que se deben llevar a cabo en las instituciones educativas.

La praxis transformadora debe ser constante y duradera para lograr los objetivos propuestos, rescatando la tradición del pensamiento en el sentido de la educación como eje fundamental para la liberación y transformación de las sociedades y la lectura de los docentes, primer lugar y de los estudiantes en segundo lugar.

Finalmente, se debe concientizar a los educandos para que puedan crear procesos de lectura, búsqueda, independencia y a la vez solidaridad con sus congéneres, en cualquier situación que se les presente, de esta política neoliberal que consume al atraso. Es por ello que la pedagogía transformadora significa, pensar y ejecutar científicamente las cosas, principalmente la educación: desentrañar todo el devenir que histórica y orgánicamente han sido la concepción dialéctica del mundo aplicada a la educación, para concebir la vida y el mundo como un proceso, concebir la realidad como un objeto del conocimiento, de práctica y transformación, que significa reconstruir la práctica y el conocimiento a través del pensamiento científico.

Esto quiere decir pensar en la sociedad más allá de lo establecido y combatir lo injusto desde la educación, partiendo de la realidad, conocerla correctamente para cambiarla. No se debe olvidar que frente a este proceso de enseñanza siempre se debe contextualizar el quehacer educativo en el aula porque a partir de allí es de donde se puede iniciar y avanzar, formar individuos con valores, capaces y pensantes frente a la problemática que los circunda, desde el ejercicio de la lectura de textos propios del contexto cultural de los estudiantes.

\section{Agradecimientos}

Este artículo es resultado de un proceso de investigación de la Maestría en Educación de la Universidad de Medellín, que tuvo como epicentro a la Institución 
Educativa de Nuestra Señora de las Mercedes del municipio de Quibdó (Chocó) entre el 2018 y el 2019 en estudiantes del grado noveno de aquella institución.

\section{Referencias}

Ander-Egg, E. (2003). Repensando la investigación Acción-Participación. Buenos Aires: Grupo editorial Lumen Hvmanitas.

Araujo, N. y Delgado, T. (2003) Textos de teorías y críticas literarias (De formalismo a los estudios poscoloniales). Habana / México: Universidad de La Habana / UAM-I.

Austin, J. L. (1962). How to Do Things With Words. Oxford: At The Clarendon Press.

Bachioqui, L. E. (2010). La interpretación y los actos de habla. Mutatis Mutandis, 3(2), 333-348.

Cassany, D., Luna, M. y Sanz, G. (1998). Antropología filosófica. Introducción a una filosofía de la cultura. México: Fondo de Cultura Económica.

Cerchiaro, E., Paba, C. y Sánchez, L. (2005). El acto del habla desde los textos narrativos. Barcelona: Herder.

Condemarín, J. (2001). La educación como práctica de la libertad. México: Siglo XXI editores.

Cueto, Á. (1999). Comprender y transformar la enseñanza. Madrid: Morata.

Defior, M. (2000). Pedagogía de la esperanza: un reencuentro con la pedagogía del oprimido. México: Siglo XXI.

Goodman, A. (1982). La alternativa pedagógica. Barcelona: Nova Terra.

Jackson, P. (1998). La vida en las aulas. Madrid: Morata.

Lewin, K. (1939). Teoría de campo y experimento en psicología social: conceptos y métodos. Revista estadounidense de sociología, 44(6), pp. 271-299.

Malagón, M. F. (2003). Planificación institucional en la educación: un reto estratégico de cambio para los gerentes educativos innovadores. Bogotá: 3R Editores.

Maqueo, A. M. (2006). Lengua, aprendizaje y enseñanza: el enfoque comunicativo de la teoría a la práctica. México: Limusa.

Mayoral, J. A. (comp.). (1987). Pragmática de la comunicación literaria. T. A. VAN DIJK, Studies in the Pragmatics of Discourse, 5, 243-263.

Mosquera, J. (1999). La Etnoeducación y los estudios afrocolombianos en el sistema escolar. Bogotá: Docentes editores.

Moya, P. C. (2009). Aproximación pragmática a los conceptos de acto de habla y de acción comunicativa: desde el Jardín de Freud. Revista de Psicoanálisis, (9), 229-244.

Proyecto Educativo Institucional. (PEI). Institución Educativa Agropecuaria Nuestra Señora de las Mercedes. Villa Conto-Río Quito. 2016. Recuperado de http://www.mineducacion.gov.co/1621/ articles293647archivo_pdf_plansectorial.pdf

Sánchez, D. (2011). El lenguaje: herramienta de reconstrucción del pensamiento. Razón y palabra, 15(72), 1-26.

Searle, J. (1982). La filosofía del lenguaje. Diálogo con John Searle. México: Fondo de Cultura Económica.

Solé, R. (2006). La pedagogía crítica. Una manera ética de generar procesos educativos. Revista de Humanidades, 28, 108-119. 